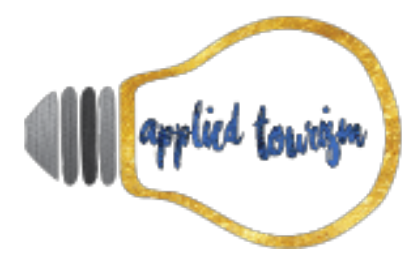

\title{
A PERCEPÇÃO DOS VISITANTES DE FERNANDO DE NORONHA (PE): Estudo de Caso do Projeto TAMAR
}

\author{
Ricardo Javier Hurtado Alvarez \\ Bacharel em Turismo \\ Laboratório de Turismo em Áreas Naturais - UEPG \\ javierhurtado91@hotmail.com
}

Lourival Dutra Neto

Bacharel em ciências biológicas

Gestor do Centro de Visitantes do Projeto TAMAR - Base Fernando de Noronha lourival.dutra@tamar.org.br

Jasmine Cardozo Moreira

Pós-Doutora

Universidade Estadual de Ponta Grossa jasminecardozo@gmail.com

Recebido: 28 de junho, 2017

Aprovado: 21 de fevereiro, 2018

\section{RESUMO}

Em 1984 o Projeto TAMAR criou uma base em Fernando de Noronha, arquipélago com grande fluxo turístico, onde realiza atividades de conservação, pesquisa científica e educação ambiental em função da preservação das espécies de tartarugas marinhas que ocorrem no Brasil. No Centro de Visitantes do Projeto TAMAR em Fernando de Noronha há um Livro de Sugestões/Reclamações, onde os visitantes podem deixar a sua opinião sobre aspectos gerais da ilha. O objetivo foi verificar, nos 96 comentários deixados em 2016 no Livro de Sugestões/Reclamações, a percepção do visitante e o que pode ser melhorado no Arquipélago, além de classificar os comentários, de forma que possam ser direcionados para as devidas instituições. Como resultados observou-se que podem ser melhorados aspectos referentes à infraestrutura, às prestações de serviços e ao turismo sustentável.

Palavras-chaves: Projeto Tamar; Fernando de Noronha; Ecoturismo. 


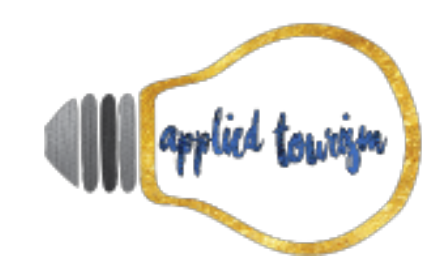

Volume 3, número 1, 2018, p. 127-146

\section{INTRODUÇÃO}

\section{Fernando de Noronha}

O Arquipélago de Fernando de Noronha, localizado no Oceano Atlântico, foi descoberto em 1501 pelo português Fernão de Loronha quando realizava uma expedição desde Lisboa com destino à terra de Vera Cruz. Possui uma extensão de vinte e seis quilômetros quadrados e fica a 545 quilômetros do estado de Pernambuco e 379 quilômetros de Rio Grande do Norte (MARSHALL, JENKINS, CLEARY, 2009). Com o passar dos anos o arquipélago foi sendo utilizado de diferentes formas, tornando-se presídio comum de 1830 a 1910, passou a ser presídio político em 1938, e em 1942, pelo Decreto n 4.102, de 9 de fevereiro de 1942, se converteu em base militar pela sua localização estratégica no atlântico (PESSOA, 2014).

Em 1986 foi implantada a primeira Unidade de Conservação (UC) de Fernando de Noronha, a Área de Proteção Ambiental (APA), que foi criada pelo Decreto n 92.755 de 05 de junho de 1986, abrangendo uma área de 884,1600 hectares. E dois anos depois foi criada a outra UC de Fernando de Noronha, que é o Parque Nacional Marinho de Fernando de Noronha (PARNAMAR) criado pelo Decreto n 96.693 de 14 de setembro de 1988, abrangendo uma área de 10.927,64 hectares. Sendo a maior das duas. A instituição que faz a gestão ambiental de todas as UCs no Brasil, instituídas pela União, é o Instituto Chico Mendes da Biodiversidade (ICMBio), que tem o papel de propor, implantar, gerir, proteger, fiscalizar e monitorar essas áreas (ICMBIO, 2017).

No ano 2001 Fernando de Noronha ganhou o título de Patrimônio Mundial da Humanidade, outorgado pela Organização das Nações Unidas para a Educação, a Ciência e a Cultura (UNESCO) devido à importância do arquipélago para a alimentação e reprodução de atuns, tubarões, tartarugas marinhas, e mamíferos marinhos. E pela presença de uma das maiores concentrações de aves marinhas tropicais do Atlântico Ocidental (UNESCO, 2009). Atualmente há um estudo que visa propor Fernando de Noronha para que receba o título de Geoparque outorgado pela UNESCO (MOREIRA, 2015). 


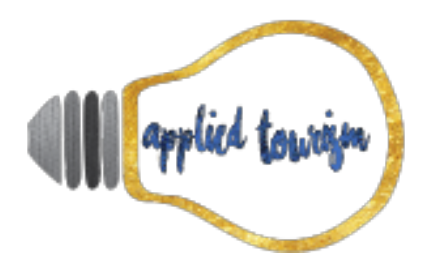

Volume 3, número 1, 2018, p. 127-146

Uma UC é uma área onde, através de um estudo prévio, se pretende implantar normas e formas de uso em função da preservação e/ou conservação do meio ambiente. No Brasil podem ser municipais, estaduais e federais. E em função do seu uso existem duas categorias: Unidades de Conservação de Proteção Integral e Unidades de Conservação de Uso Sustentável. Dentro da primeira categoria encontramos UCs que não podem ser habitadas pelo homem, sendo utilizadas de forma indireta em atividades como pesquisa científica e turismo. Por outro lado, nas UCs de uso sustentável é permitida a presença de moradores, tendo como objetivo atingir um equilíbrio entre a conservação da natureza e a sua sustentabilidade na hora de utilizar os seus recursos naturais (WWF, 2017; Brasil, 2000).

As UCs de uso sustentável são: Áreas de Proteção Ambiental, Áreas de Relevante Interesse Ecológico, Florestas Nacionais, Reservas Extrativistas, Reservas de Fauna, Reservas de Desenvolvimento Sustentável e Reservas Particulares do Patrimônio Natural. E as UCs de proteção integral são: Estações Ecológicas, Reservas Biológicas, Parques Nacionais, Monumentos Naturais e Refúgios da Vida Silvestre.

Portanto, em Fernando de Noronha encontramos uma UC de uso integral, que é o PARNAMAR, e uma UC de uso sustentável, a APA (Figura 01). É importante dar ênfase nesta característica, já que ao ser um destino turístico consolidado que só no ano de 2016 recebeu noventa e um mil visitantes (RAMOS, 2017), deve atingir um equilíbrio entre o fluxo turístico e a conservação do meio ambiente. 


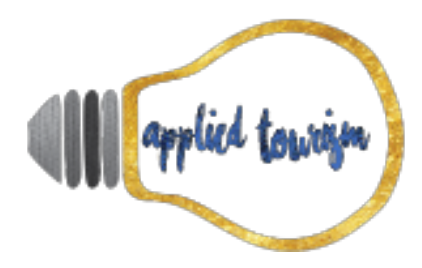

Volume 3, número 1, 2018, p. 127-146

Figura 01 - APA e PARNAMAR

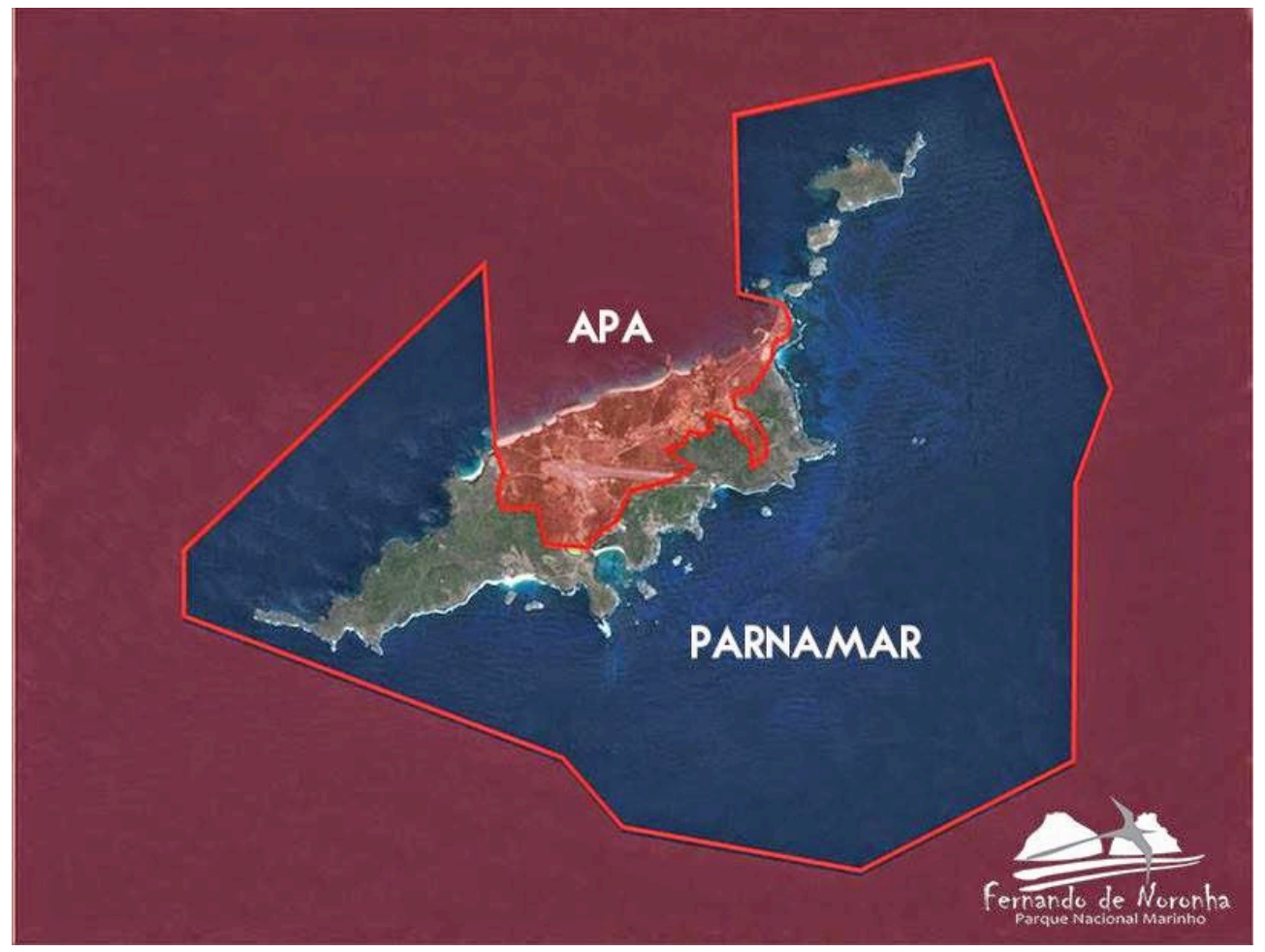

Fonte: www.rotanoronha.com.br

Desta forma, na APA encontramos algumas características que não encontramos no PARNAMAR, tais como serviços de hospedagem e alimentação, posto de saúde, acesso em estrada pavimentada, pesca regulamentada, saneamento, aeroporto, circulação de veículos motorizados, entre outros. Por outro lado, no PARNAMAR de Fernando de Noronha existe horário de visita, áreas onde só pode ser realizada visita com guia de turismo certificado, agendamento para visitar determinados atrativos naturais em função de não extrapolar sua capacidade de carga, entre outros.

A seguir, será feita uma análise breve das duas UCs de Fernando de Noronha e também as instituições governamentais e não-governamentais que nelas atuam. 


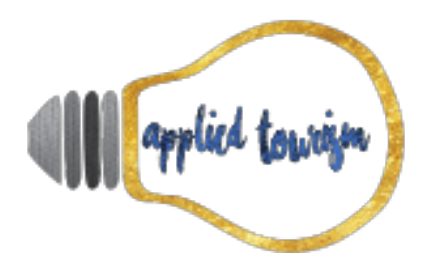

Volume 3, número 1, 2018, p. 127-146

\section{Área de Preservação Ambiental de Fernando de Noronha}

A APA de Fernando de Noronha é onde se concentra o núcleo de moradias, hospedagens, restaurantes e prestações de serviço em geral que fazem possível acontecer a atividade turística no arquipélago.

Conforme o Plano de Manejo da APA de Fernando de Noronha a sua finalidade é criar em longo prazo a conciliação da conservação ambiental com as atividades humanas desenvolvidas, melhorando a qualidade de vida da população que ali reside. E que dentro dos seus programas de ação indica aspectos urbanísticos e habitacionais, adequação de infraestrutura, saneamento, ordenamento da atividade pesqueira, apoio à atividade agropecuária, recuperação de áreas degradadas, inserção do jovem ilhéu, entre outros (ICMBIO, 2005).

\section{Taxa de Preservação Ambiental}

Com o objetivo de gestão dos potenciais impactos ao meio ambiente que o turismo poderia trazer ao arquipélago é realizado um controle migratório que determina quantos turistas podem ingressar por dia, e também é aplicado o pagamento da Taxa de Preservação Ambiental (TPA) aos turistas que permanecem na ilha. A TPA é proposta pelo governo de Pernambuco, como um instrumento e alternativa encontrada para a preservação ecológica de Fernando de Noronha (ICMBIO, 2005).

O valor da TPA é definido pelos dias de permanência dos turistas na ilha, e o valor é inteiramente destinado ao governo de Pernambuco, respaldado pela Lei ${ }^{\circ} 11.704$, de 29 de novembro de 1999. É importante mencionar também que o valor da TPA não é contemplado no preço dos pacotes turísticos que as empresas prestadoras de serviços oferecem, fazendo que o turista desembolse esse gasto de forma separada antes de ingressar na ilha. (ICMBIO, 2005). O valor é definido pelos dias de permanência, sendo R\$ 68,74 por dia. 


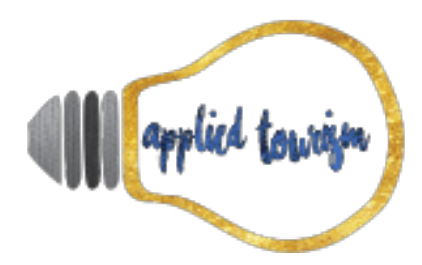

Volume 3, número 1, 2018, p. 127-146

\section{Parque Nacional Marinho de Fernando de Noronha}

O PARNAMAR de Fernando de Noronha abrange a maior parte do Arquipélago, com exceção das áreas da Vila dos Remédios, Vila do Boldró, vila Três Paus, residência da aeronáutica, Vila militar, morros do Meio e do Pico, e uma faixa de praia que vai desde a Praia da Cacimba até o Porto do Santo Antônio. Além da ilha principal que é a única habitada, Fernando de Noronha possui outras ilhas no seu entorno que também são parte do PARNAMAR, como as ilhas Rasa, Rata, do Frade, do Meio e Sela Gineta.

As áreas do parque, tais como a Baía do Sueste, Baia dos Golfinhos, Praia do Leão e Praia do Sancho possuem horário para visitação, que é das 9 h00 às 16h00. E para poder usufruir dos atrativos naturais inseridos dentro do PARNAMAR é necessário obter o ingresso, que de acordo com Portaria do Ministério do Meio Ambiente 135/2010, tem a validade de dez dias corridos, com o valor de $\mathrm{R} \$ 99,00$ para brasileiros e $\mathrm{R} \$ 198,00$ para estrangeiros. Ou seja, além da TPA, também deve ser pago o ingresso para entrar nas áreas do parque (PARQUE NACIONAL MARINHO FERNANDO DE NORONHA, 2017).

A verificação de compra do ingresso é realizada nos Pontos de Informação e Controle (PIC), localizados nos locais de acesso a alguns atrativos do parque. Nos PICs pode-se encontrar venda de souvenirs, alimentação, painéis informativos, entre outros. É importante mencionar que a gestão desta infraestrutura de apoio no PARNAMAR é realizada pela Econoronha, que foi a vencedora num processo de licitação para prestação de serviços de apoio à visitação turística. Realizando a cobrança de ingressos, melhorando o acesso às praias, fornecendo serviços de alimentação, a concessão com a Econoronha busca atingir a sustentabilidade e manejo correto do ecoturismo dentro do parque (PARQUE NACIONAL MARINHO FERNANDO DE NORONHA, 2017). 


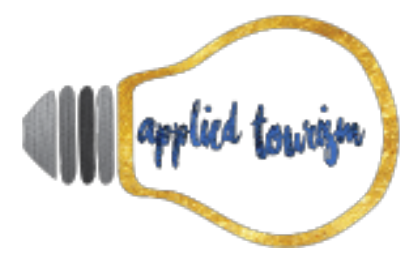

Volume 3, número 1, 2018, p. 127-146

Figura 02 - PIC Econoronha

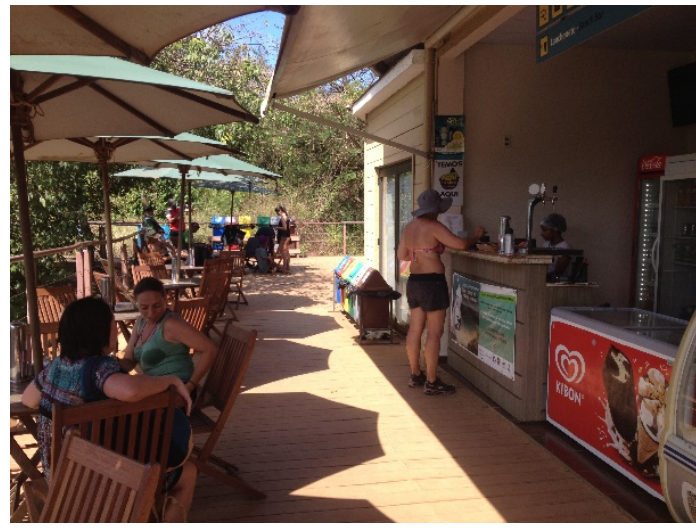

Figura 03 - Trilha suspensa

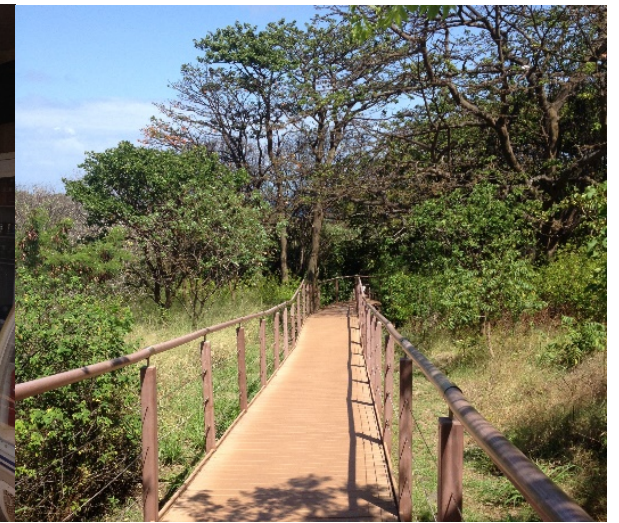

Fonte: autores (2018).

Na Figura 02 aparece a lanchonete de um PIC da Econoronha, que está localizada no ponto de acesso à Praia do Sancho. E ao lado, na Figura 03, observa-se a trilha suspensa instalada pela Econoronha que dá acesso aos atrativos nessa área. O agendamento de algumas trilhas e passeios guiados dentro do PARNAMAR é realizado só em determinados pontos de venda de ingressos.

\section{Projeto TAMAR}

O Projeto TAMAR nasce no final dos anos 70 quando um grupo de estudantes da Faculdade de Oceanografia da Universidade Federal de Rio Grande do Norte começou fazer um levantamento de dados sobre as áreas de ocorrência das cinco espécies de tartaruga marinha que ocorrem no Brasil. Após o levantamento de dados realizado em todo o litoral brasileiro, em 1982 surgem as primeiras três bases do Projeto TAMAR localizadas em Pirambu/SE, Comboios/ES e Praia do Forte/BA (PROJETO TAMAR, 2011).

Atualmente o Projeto TAMAR possui vinte e cinco bases no Brasil, trabalhando sob os eixos da inclusão social, pesquisa científica e educação ambiental, buscando criar consciência sobre a importância de conservar o meio ambiente e proteger as diferentes espécies de tartarugas marinhas que se encontram no litoral brasileiro. 


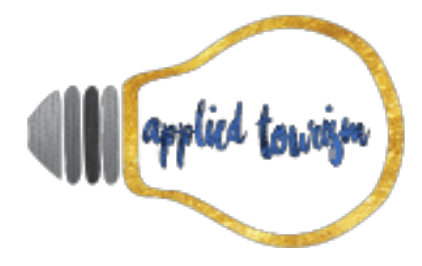

Volume 3, número 1, 2018, p. 127-146

A quarta base do Projeto TAMAR a ser criada foi a de Fernando de Noronha, no ano de 1984. Nesta base acontece o Programa de Ecoturismo que possibilita que os turistas participem de atividades de educação ambiental, tais como Captura Intencional de Tartarugas Marinhas, Tartarugada, Visitas Guiadas no Museu Aberto da Tartaruga Marinha e Ciclo de Palestras Ambientais (GERHARDT, 2015). As primeiras duas atividades de educação ambiental são realizadas nas praias e as outras duas no Centro de Visitantes do Projeto TAMAR em Fernando de Noronha.

O Ciclo de Palestras Ambientais, que acontece diariamente no Centro de Visitantes, vem sendo realizado há vinte anos e são apresentados temas sobre a fauna do local, as duas UCs, o ecoturismo e uma programação especial nos domingos em que pesquisadores que visitam a ilha são convidados para apresentar seus trabalhos (MOREIRA; ROBLES; BELINI, 2009). No Auditório do Centro de Visitantes do Projeto TAMAR há um Livro de Sugestões/Reclamações, que é o objeto de estudo do presente trabalho, onde os turistas que frequentam o Ciclo de Palestras Ambientais têm a liberdade de deixar seus comentários sobre o que pode ser melhorado na ilha.

Figura 04 - Livro de Sugestões/Reclamações dentro do auditório do Centro de Visitantes

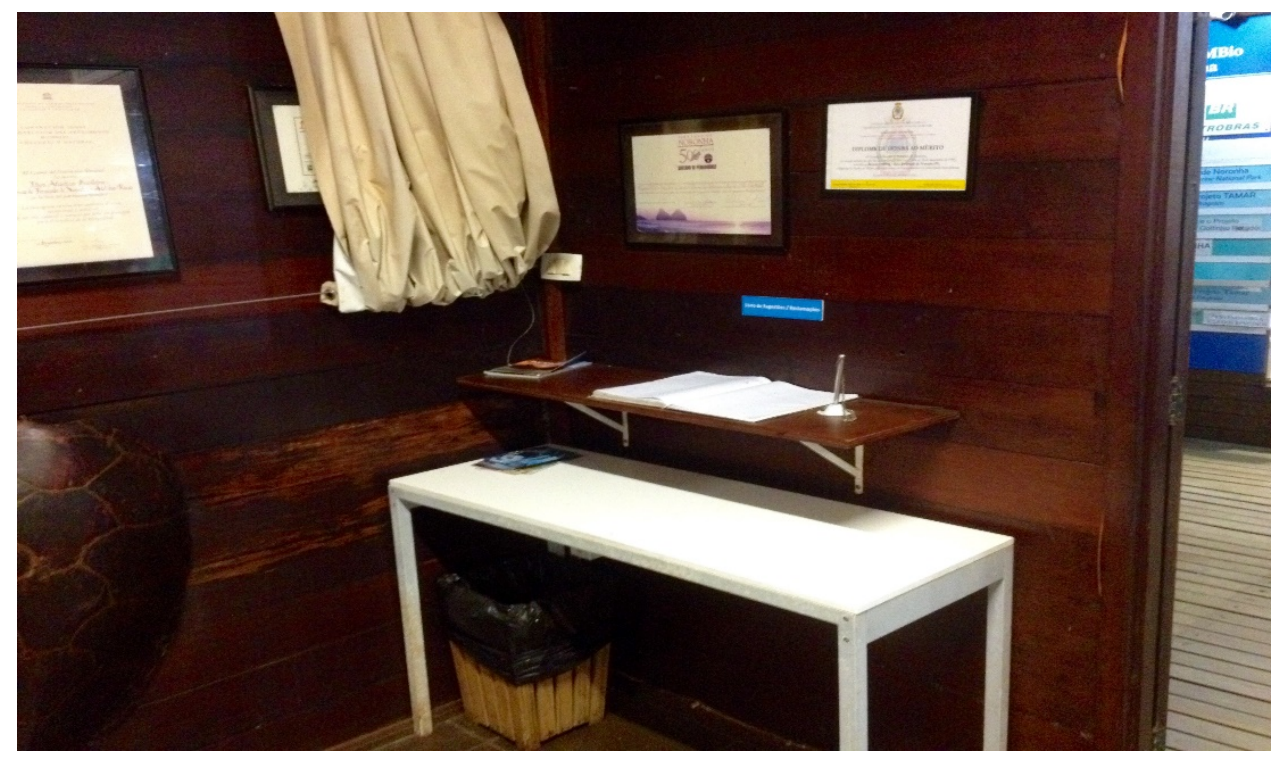

Fonte: Acervo pessoal. 


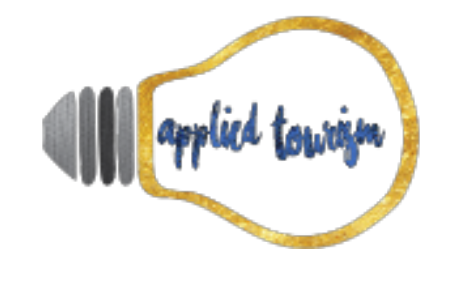

Volume 3, número 1, 2018, p. 127-146

Na Figura 04 pode-se ver o Livro de Reclamações/Sugestões localizado no interior do Auditório do Projeto TAMAR. Todas as noites antes do início da palestra, é feita uma apresentação pelos estagiários ou colaboradores do Tamar. Nessa apresentação, o livro é mencionado, no sentido de estimular os visitantes para que deixem seus comentários, após a palestra.

\section{METODOLOGIA}

A metodologia utilizada para este trabalho foi bibliográfica e com base documental, sendo uma análise dos dados coletados através do Livro de Reclamações/Sugestões do Projeto TAMAR em Fernando de Noronha. Noventa e seis comentários foram escritos no livro ao longo do ano 2016, os quais foram analisados para tentar entender a percepção que os turistas têm do arquipélago. O livro funciona como um espaço livre para quem quiser deixar os seus comentários e existe desde 2008.

Eles foram classificados no sentido de entender para quais instituições deveriam ser direcionados, tentando assim, criar um instrumento que ajude a determinar como pode-se melhorar a qualidade da viagem dos turistas, qualidade de vida dos moradores, e que ajude a atingir o conceito de produto turístico sustentável na ilha.

Devido à complexidade em classificar sugestões e reclamações, as mesmas foram analisadas identificando-se frases pontuais e direcionadas especificamente à instituição correspondente, ou de forma que fossem vinculadas ao que lhe compete a cada instituição. Comentários não específicos, ou que não foram possíveis de vincular ou relacionar às instituições contempladas, não foram utilizados, devido dificuldade em classificá-los.

Desta forma as categorias em que foram classificados os comentários foram: Administração, ICMBio, Companhia Energética de Pernambuco (CELPE), Projeto Golfinho Rotador, empresas privadas e Projeto TAMAR. Há ênfase em comentários positivos ou negativos. 


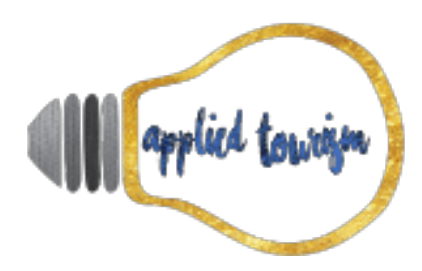

Volume 3, número 1, 2018, p. 127-146

Cada uma das sugestões e reclamações escritas no livro pode ter mais de um apontamento, ou seja, quando se encontrou em um mesmo comentário várias sugestões, elas foram individualizadas no gráfico.

Figura 05 - Exemplo de comentário

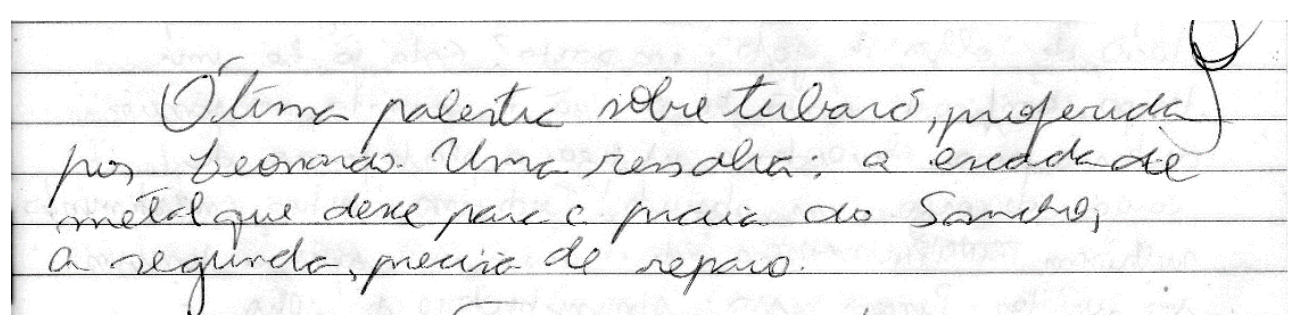

Fonte: Livro de Sugestões/Reclamações do Projeto TAMAR em Fernando de Noronha.

A Figura 05 exibe um exemplo de comentário escrito em janeiro de 2016, nela pode-se observar que apesar de ser um comentário, nele encontram-se dois apontamentos. Um deles é sobre o Ciclo de Palestras Ambientais realizadas diariamente no Centro de Visitantes do Projeto TAMAR, e o outro é sobre a infraestrutura da Praia do Sancho dentro do PARNAMAR. Os dois apontamentos, num mesmo comentário, são individualizados e expostos nos resultados. As duas instituições envolvidas são o Projeto TAMAR, encarregado do Ciclo de Palestras Ambientais; e o ICMBio, que é o encarregado da gestão do PARNAMAR.

\section{RESULTADOS}

A seguir, serão apresentados os resultados dos comentários que foram escritos no Livro de Reclamações/Sugestões do Projeto TAMAR, e que puderam-se vincular com as instituições às quais foram direcionados.

\section{Administração}

Foram direcionadas para a administração da ilha vinte e quatro comentários, todos negativos. 
Gráfico 01 - Apontamentos negativos direcionados à administração

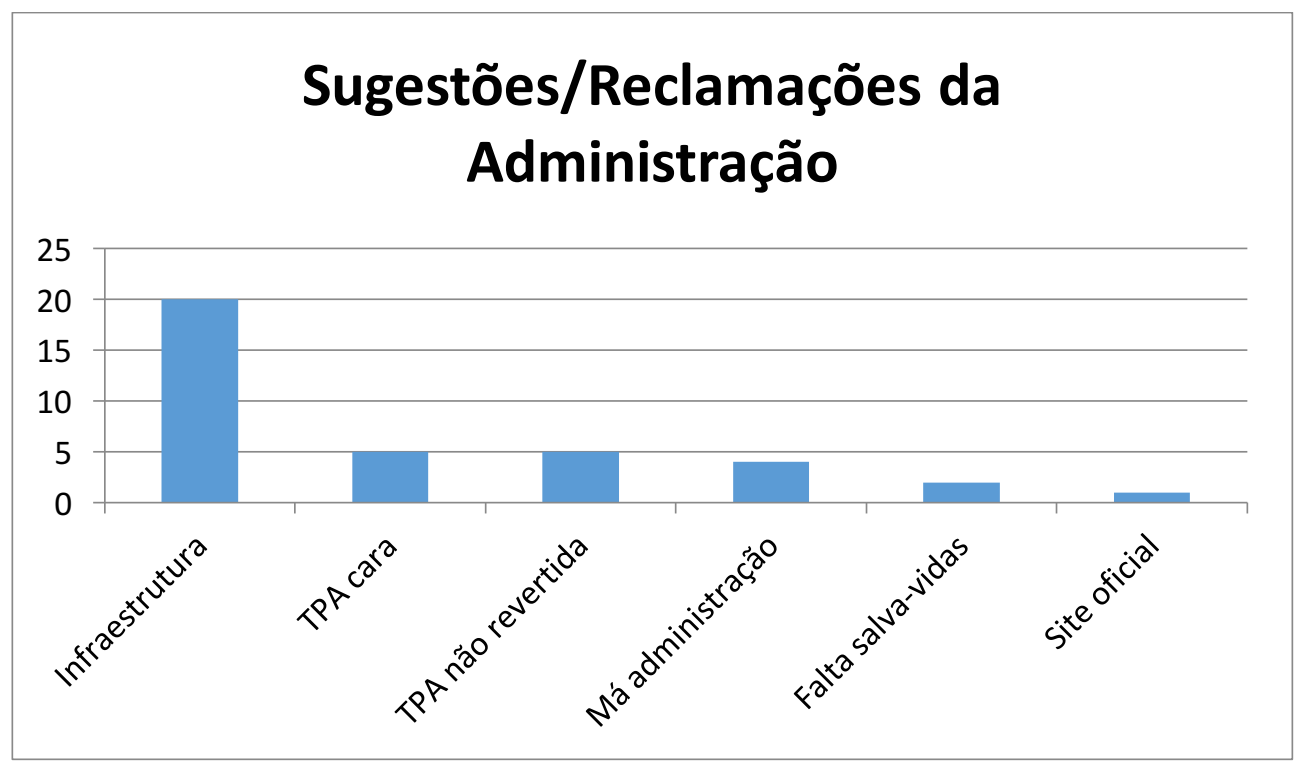

Fonte: autores (2018).

No Gráfico 01 observa-se que desses vinte e quatro comentários, houve 20 apontamentos de que a ilha precisa melhorar a sua infraestrutura. Outros quatro visitantes consideram que a ilha tem uma má administração e outros dois reclamam que faltam salva-vidas nas praias. Cinco comentários mencionam que a Taxa de Preservação Ambiental (TPA) cobrada ao ingressar na ilha é muito cara, enquanto outros cinco pensam que a referida taxa não é revertida para a ilha. Um comentário fez menção à falta de informação no site oficial de Fernando de Noronha. 
Volume 3, número 1, 2018, p. 127-146

Gráfico 02 - Apontamentos específicos sobre a infraestrutura

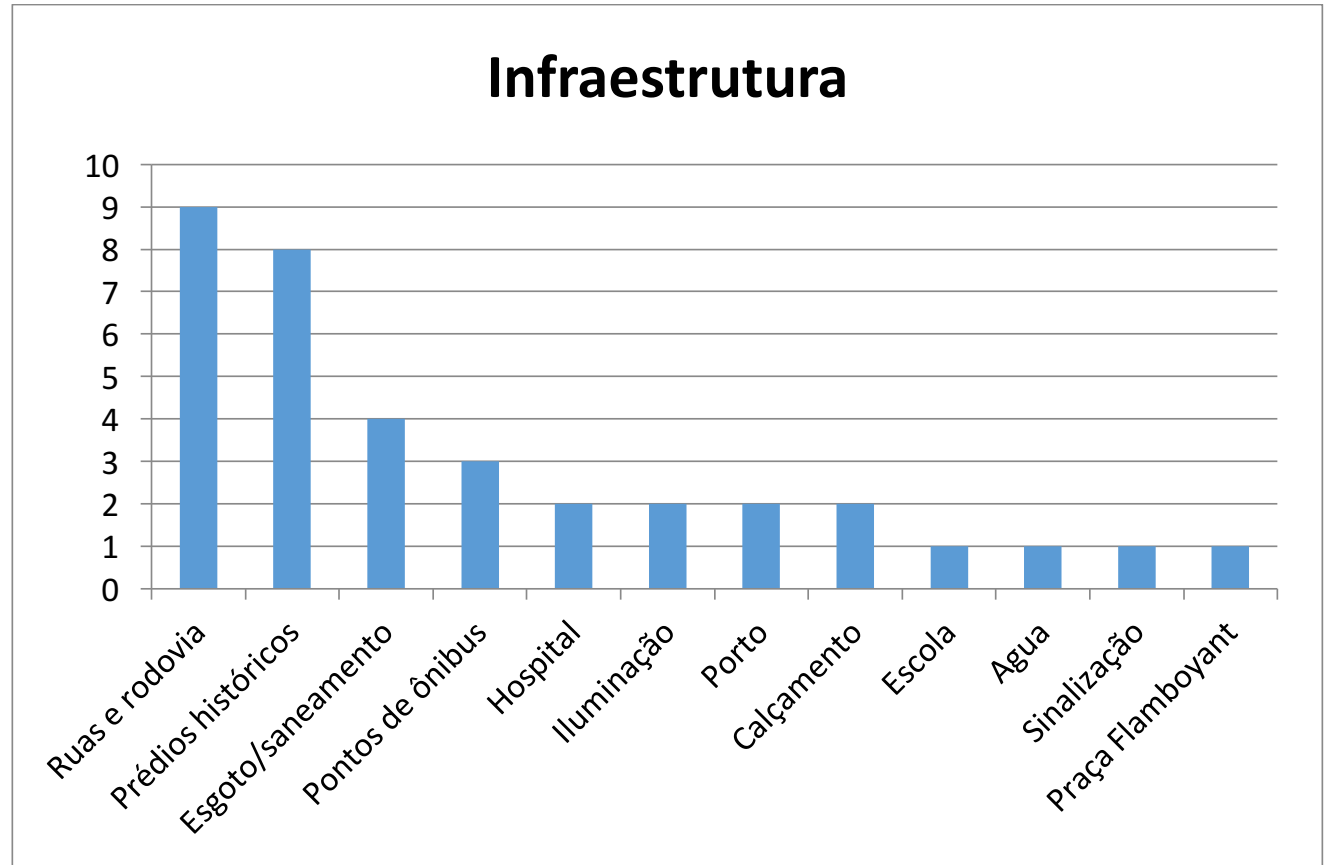

Fonte: autores (2018).

O Gráfico 02 mostra que dos 20 comentários em que se fez ênfase à necessidade de melhorar a infraestrutura da ilha, nove apontamentos mencionaram as ruas e a rodovia, oito os prédios históricos em mal estado, quatro o saneamento e esgoto, três os pontos de ônibus, dois o hospital, dois a iluminação, dois o porto, dois o calçamento, um a escola, um a água, um a sinalização e um o mal estado da Praça Flamboyant.

\section{Instituto Chico Mendes da Biodiversidade - ICMBio}

Para o ICMBio foram direcionados 23 comentários, dos quais 21 foram negativos e dois positivos. 


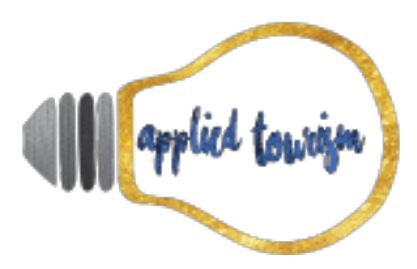

Volume 3, número 1, 2018, p. 127-146

Gráfico 03 - ICMBio

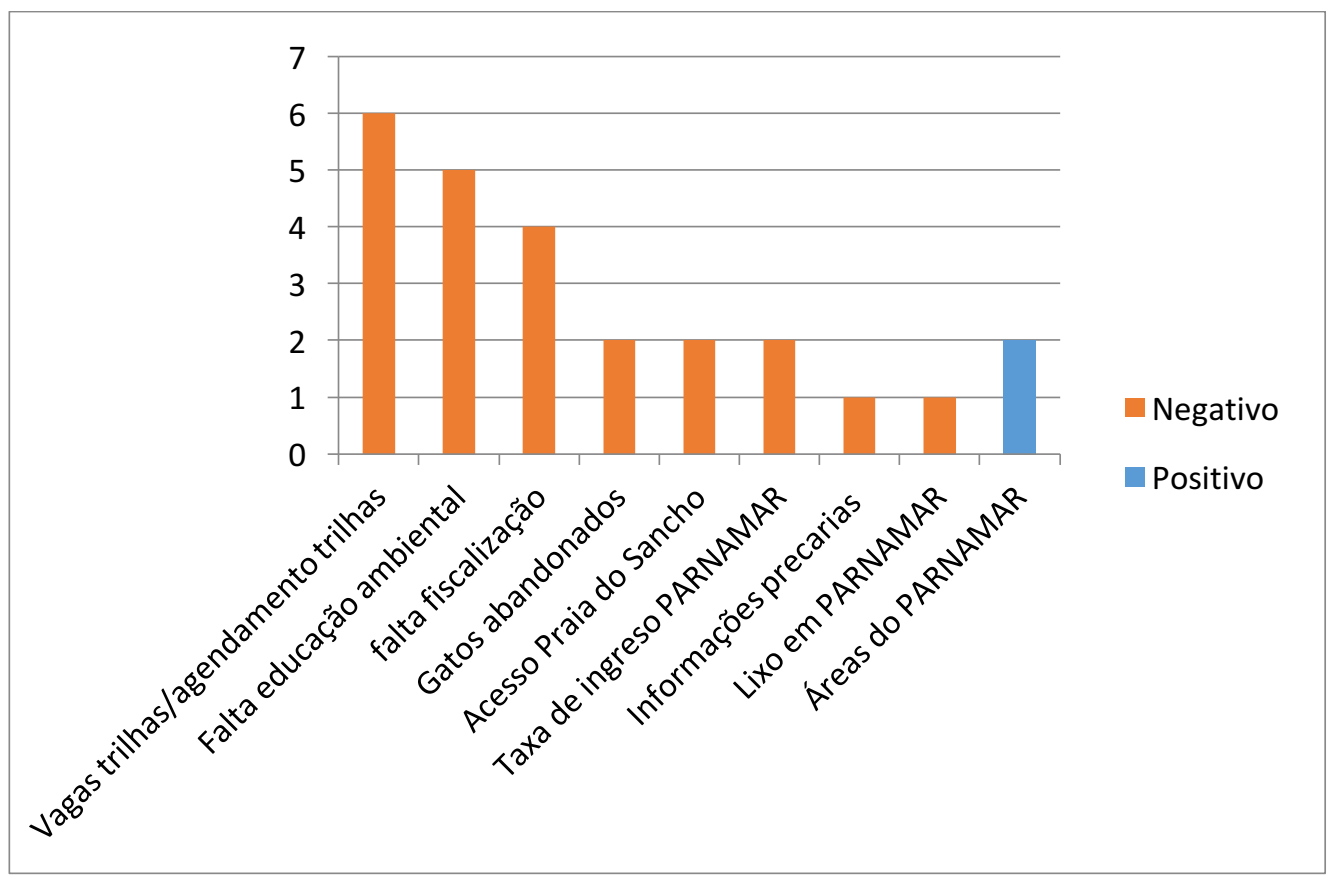

Fonte: autores (2018).

No Gráfico 03 podemos observar que foi mencionado seis vezes a necessidade de melhorar o agendamento para fazer as trilhas, pois quando os turistas tentavam agendar, muitas vezes já não encontravam vagas disponíveis. É importante essa colocação, pois cada área do PARNAMAR tem a sua determinada capacidade de carga.

A falta de educação ambiental é mencionada em cinco comentários diferentes, dentre eles, visitantes disseram que faltam panfletos informativos, conscientização ambiental em geral e orientações para os turistas de como devem se comportar na ilha. A falta de fiscalização, por outro lado, foi mencionada quatro vezes. Turistas também dizem ter observado gatos abandonados na ilha em dois comentários diferentes. O acesso à Praia do Sancho, na área do PARNAMAR, foi citado duas vezes dizendo que precisa ser melhorado. No ponto de vendas de ingresso do parque, um turista considerou as informações fornecidas a ele como precárias. Outro turista fez menção que encontrou lixo em área do PARNAMAR. Por outro lado, em outros dois comentários, turistas dizem ter gostado do PARNAMAR. 


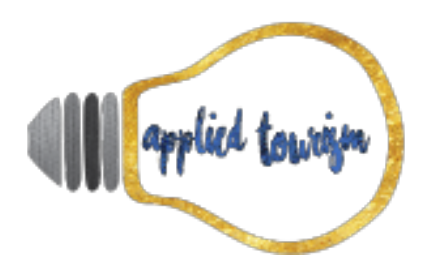

Volume 3, número 1, 2018, p. 127-146

Cabe ressaltar que alguns desses comentários dizem respeito à concessionária Econoronha e não somente ao ICMBio. E outros deveriam ser mais específicos, para que o ICMBio pudesse ter clareza do problema.

\section{Projeto TAMAR}

Para o Projeto TAMAR foram direcionados 53 comentários, dentro deles podem-se classificar 44 apontamentos positivos, sete negativos e sete considerados arbitrários. São arbitrários já que não seguem regras ou normas, ou seja, são propostas de novos temas para as palestras e do público que, segundo os visitantes, deveria participar nelas.

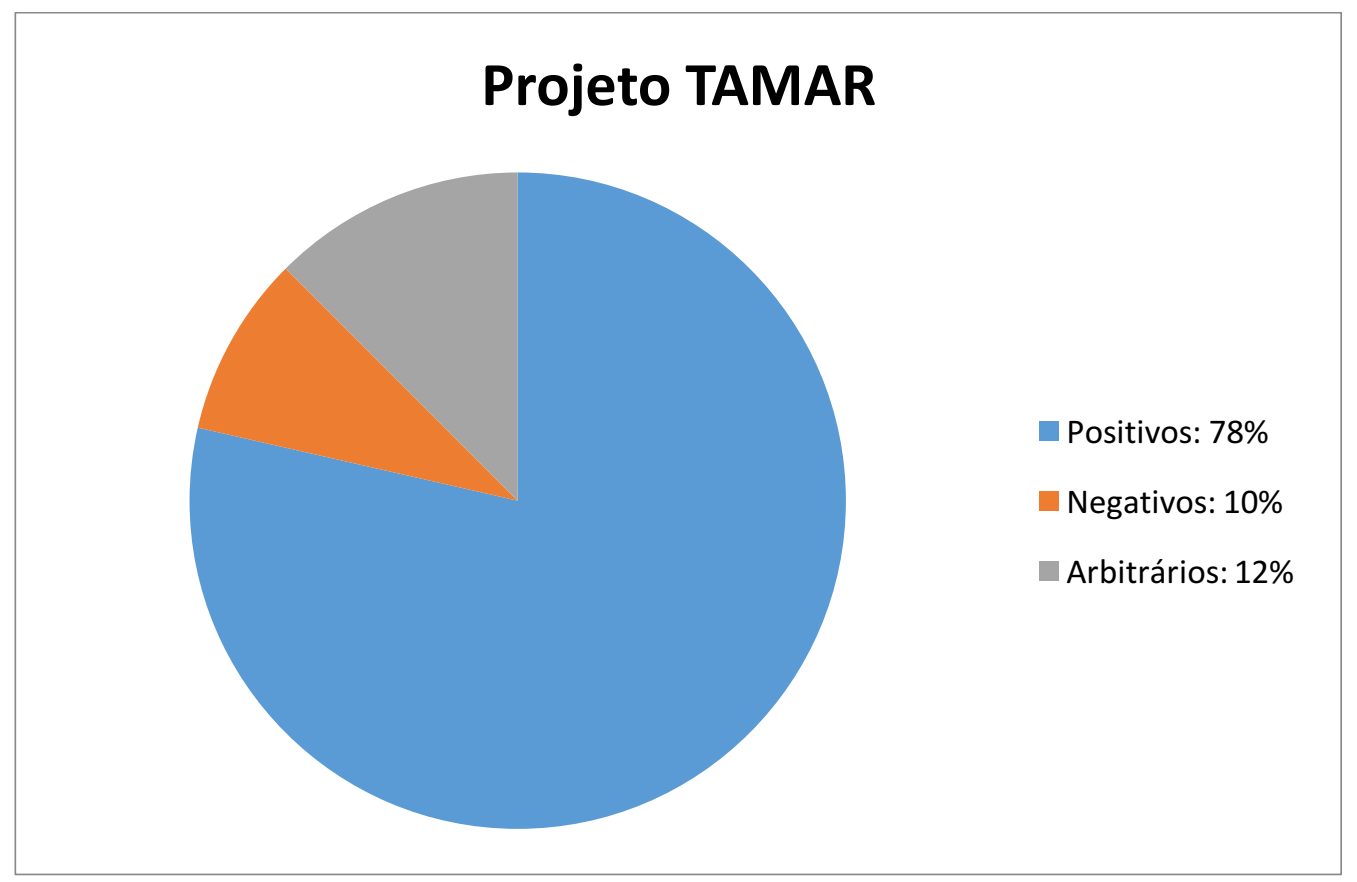

Fonte: autores (2018).

O Gráfico 04 expõe que dos 53 comentários direcionados ao Projeto TAMAR, 78\% dos apontamentos foram positivos, 10\% negativos e 12\% arbitrários. 


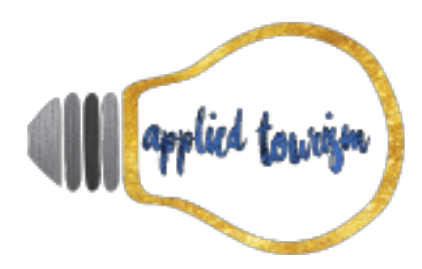

Volume 3, número 1, 2018, p. 127-146

Gráfico 05 - Apontamentos positivos Projeto TAMAR

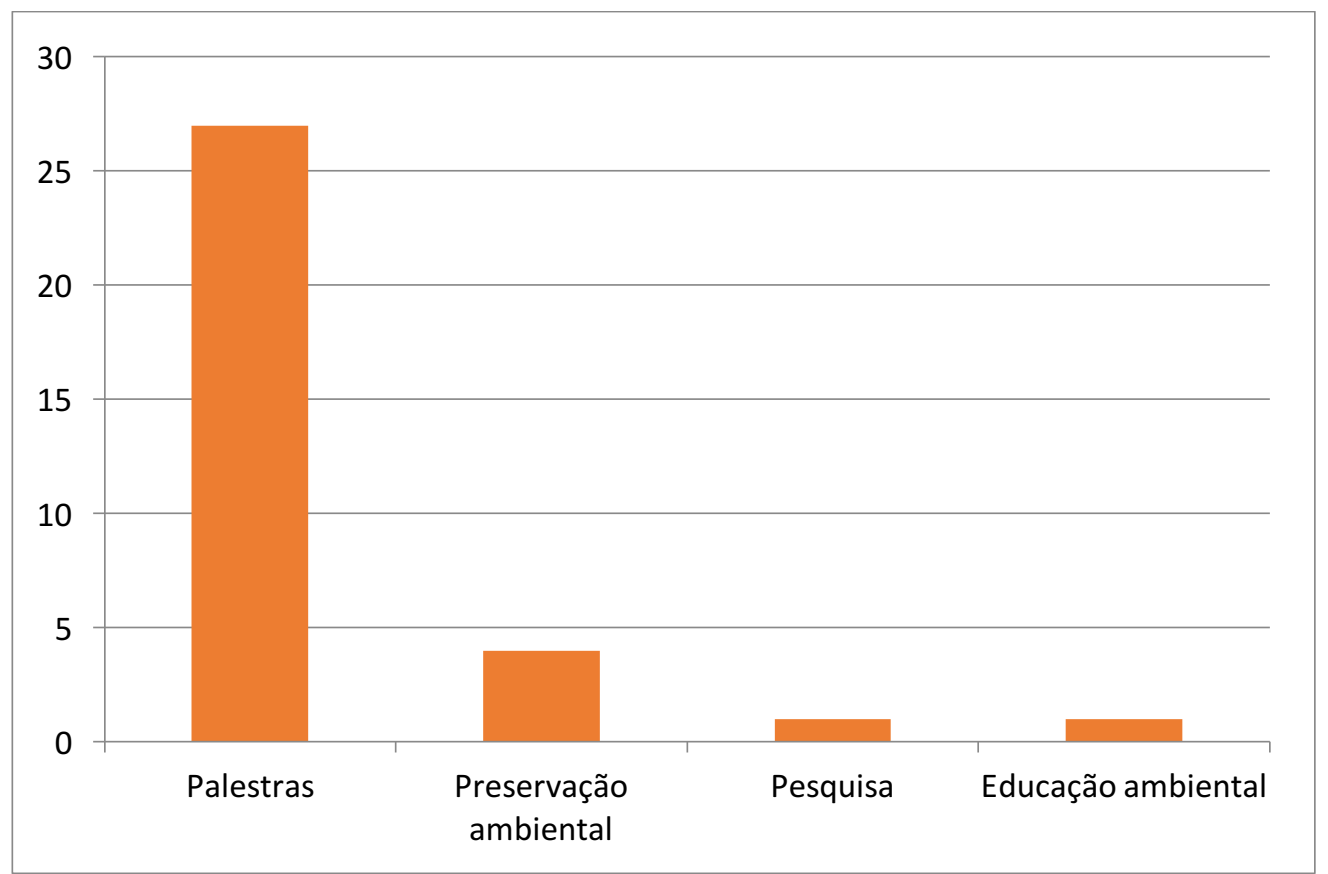

Fonte: autores (2018).

No Gráfico 05 são apresentados os apontamentos positivos feitos para o Projeto TAMAR de forma específica. Vinte e sete comentários parabenizaram ou falaram positivamente do Ciclo de Palestras Ambientais realizado diariamente no Auditório do Projeto TAMAR em Fernando de Noronha. Quatro comentários positivos mencionaram os trabalhos de preservação ambiental organizados pelo Projeto TAMAR, houve também um comentário positivo sobre os trabalhos de pesquisa e outro sobre a educação ambiental. 


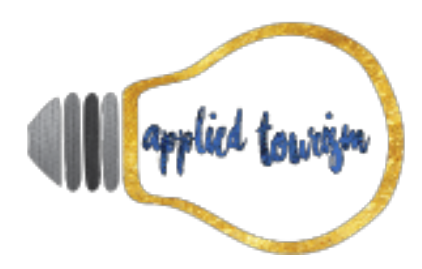

Volume 3, número 1, 2018, p. 127-146

Gráfico 06 - Apontamentos negativos sobre o Projeto TAMAR

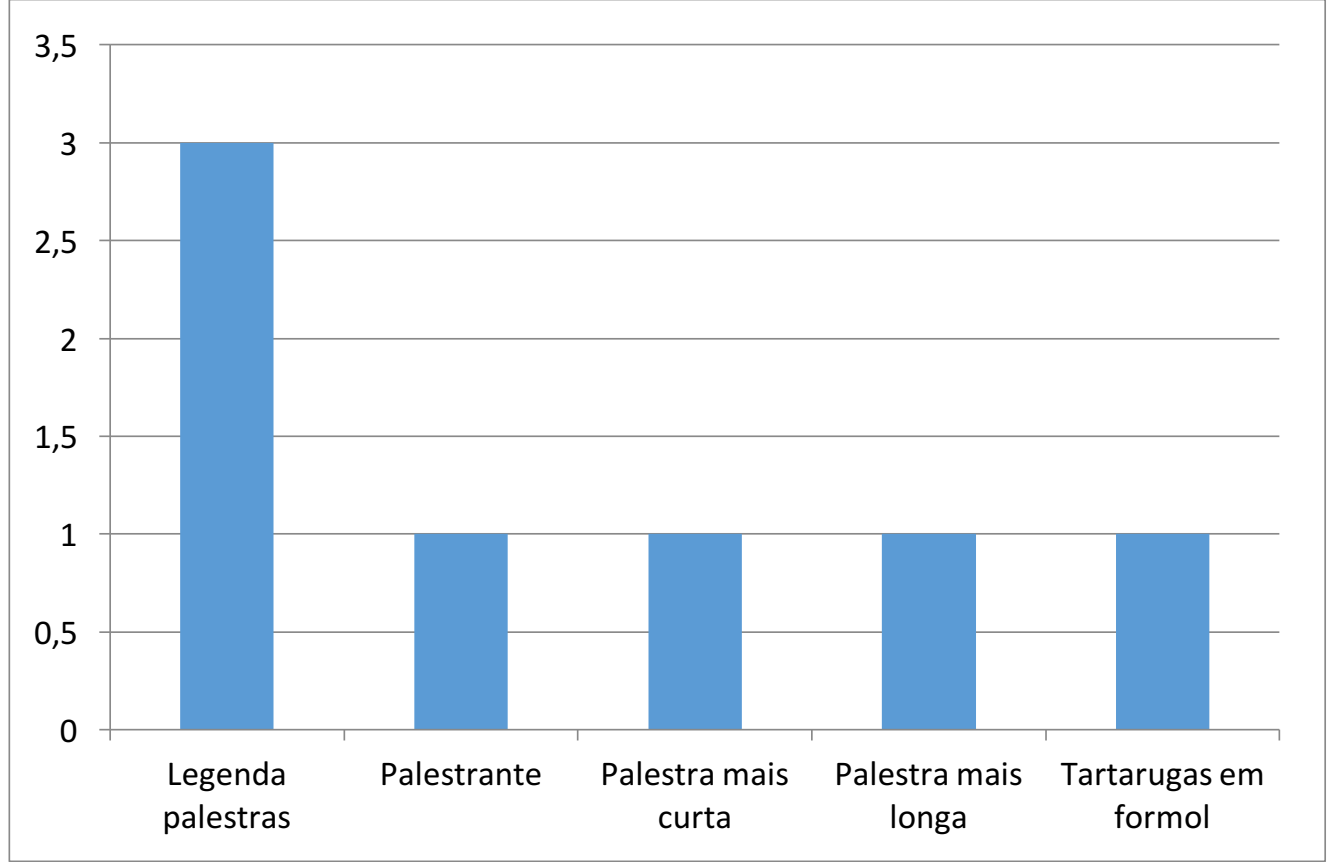

Fonte: autores (2018).

Podemos observar, no Gráfico 06, que dos sete comentários negativos direcionados ao Projeto TAMAR foram realizados três apontamentos à falta de legendas em outros idiomas nos vídeos apresentados nas palestras. Tal fato impossibilita que estrangeiros consigam compreender os temas ambientais expostos durante o vídeo. Um apontamento negativo foi direcionado a um palestrante, outro disse que a palestra deveria ser mais curta e outro que deveria ser mais longa. E por último, outro comentário negativo foi sobre a apresentação de tartarugas marinhas mortas em frascos de formol no Centro de Visitantes.

Os comentários considerados como arbitrários, foram três. Foram feitas sugestões de temas de palestras, e outros dois comentários onde os turistas consideram que as palestras deveriam ser obrigatórias para todos os turistas que chegam à ilha.

\section{Empresas privadas}

Para diferentes empresas privadas que operam no arquipélago foram direcionados oito comentários negativos. 


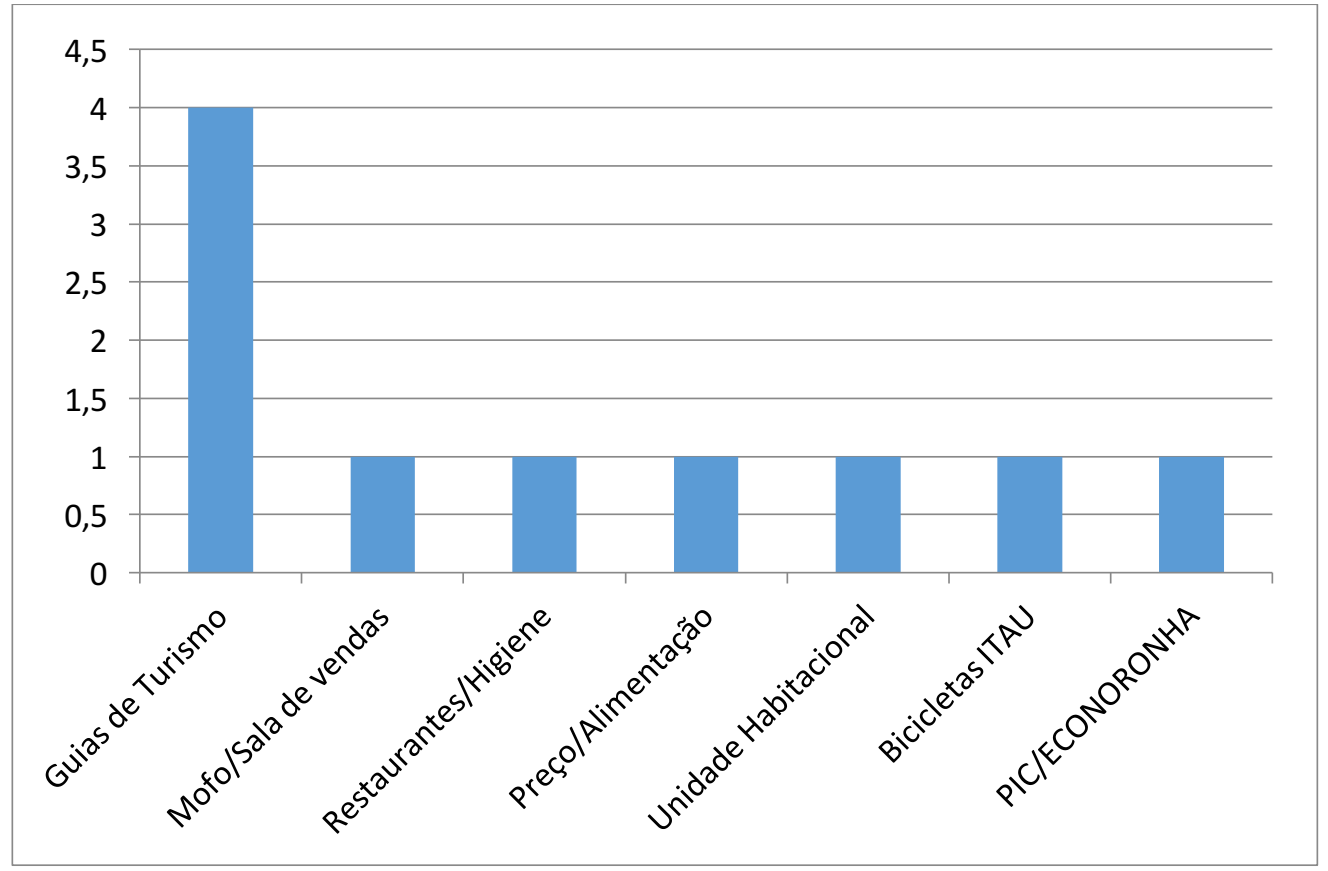

Fonte: autores (2018).

No Gráfico 07 , mostra-se que dos oito comentários, foram realizados quatro apontamentos direcionados a guias de turismo que realizaram algum tipo de mal comportamento. Tais como cutucar em animais durante atividade de mergulho guiado ou o atendimento aos turistas com informações precárias. Outros apontamentos individuais mencionaram que foi encontrado mofo em sala de vendas de camisas e canecas, falta higiene nos restaurantes, o preço da alimentação é muito alto, uma unidade habitacional de um meio de hospedagem estava em mal estado, algumas pousadas não cuidam das bicicletas que o Banco ITAU doou à ilha para os turistas utilizarem, e mau atendimento em Ponto de Informação e Controle (PIC).

\section{CELPE e Projeto Golfinho Rotador}

A CELPE recebeu um comentário negativo, que pede para verificar a ortografia da legenda em inglês do filme mostrado no Museu Interativo da CELPE. E o Projeto Golfinho Rotador recebeu um comentário, em que era sugerido que o Estado deveria assumir o Projeto. 


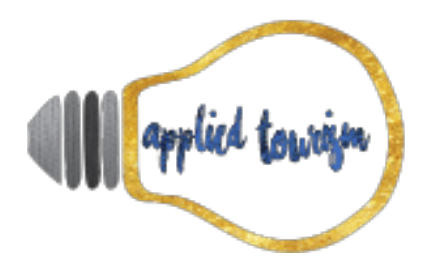

Volume 3, número 1, 2018, p. 127-146

\section{CONSIDERAÇÕES FINAIS}

Os resultados obtidos, por meio do Livro de Sugestões/Reclamações do Centro de Visitantes do Projeto TAMAR, apontam que ainda há aspectos a serem melhorados no arquipélago, na visão dos turistas. Dentre os aspectos a serem melhorados que foram mencionados encontramos infraestrutura básica, infraestrutura de apoio, prestação de serviço, e questões referentes à sustentabilidade da ilha.

Neste caso, encontraram-se poucos comentários positivos, visto que os dados foram coletados por um meio que solicita sugestões e reclamações. Portanto é necessário não os generalizar, e sim enxergá-los como um instrumento de melhoria. E da mesma forma, já que as instituições têm responsabilidades e competências diferentes, devemos analisar os resultados de forma individual para cada uma delas.

Nos apontamentos direcionados à Administração, encontramos uma recorrência nos aspectos que se referem à infraestrutura da ilha, tendo como denominador comum a melhoria da mesma, no que se refere à rodovia, prédios históricos, pontos de ônibus e o hospital. Também foram direcionados comentários sobre a TPA, expressando que o valor é alto e que aparentemente não está sendo revertida para a ilha.

O ICMBio recebeu comentários negativos sobre a forma de agendamento dos passeios guiados, tais como Atalaia, Pontinha - Pedra Alta, Abreus e São José, devido às poucas vagas. Entretanto cada um destes locais possui sua determinada capacidade de carga que deve ser respeitada, que é o resultado do número de vagas oferecidas por dia. Por outro lado, desde fevereiro de 2017, o agendamento aos passeios guiados já pode ser feito pela internet no site do PARNAMAR com até cinco dias de antecipação, facilitando assim o acesso à informação e a programação dos passeios.

Uma sugestão foi a de incluir mais meios interpretativos, como forma de educação ambiental, e aumentar a fiscalização. A maioria dos comentários feitos ao Projeto TAMAR 


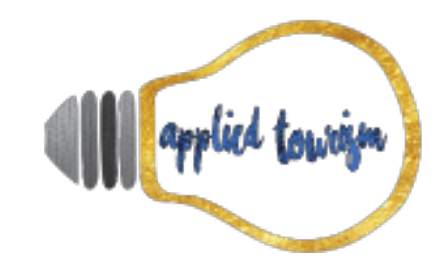

Volume 3, número 1, 2018, p. 127-146

são sobre o Ciclo de Palestras Ambientais, dado que no espaço em que se realiza essa atividade se encontra o Livro de Sugestões/Reclamações. Ao ser uma atividade de educação ambiental que não tem custo para os visitantes, é acessível para todos que queriam participar, contribuindo assim com a conscientização ambiental tanto dos turistas quanto da comunidade local, fomentando as bases do ecoturismo no arquipélago.

Prestadores de serviço da área da alimentação, hospedagem, souvenirs e guias de turismo receberam críticas na categoria "empresas privadas". Liderando os dados dessa categoria encontram-se os guias de turismo, que segundo turistas, atuaram com falta de profissionalismo ou tiveram condutas que em certa medida afetavam a sustentabilidade da ilha.

Concluindo, o Arquipélago de Fernando de Noronha é um destino de ecoturismo já consolidado no Brasil com um equilíbrio ambiental complexo, onde diversos órgãos e instituições trabalham em conjunto para atender a demanda turística e proteger o meio ambiente abrangendo a comunidade local no processo. Mesmo assim, ainda há aspectos a serem melhorados e por meio do presente trabalho pretendeu-se dar um aporte para aprimorá-los.

Com a visão de aprimorar e melhorar os aspectos negativos do arquipélago que foram apontados pelos turistas nesta pesquisa, busca-se sugerir um plano de ação ou estratégia viável. Por serem diversas instituições as que se encontram nos resultados da pesquisa, se propõe trabalhar de forma individual com as que estejam interessadas em conhecer os resultados alcançados. Expondo os aspectos positivos e negativos que os turistas deixaram nos seus comentários.

Desta forma, cada instituição pode conhecer e avaliar os dados que lhe foram direcionados, e no futuro buscar alternativas para aperfeiçoar a visitação em Fernando de Noronha. 


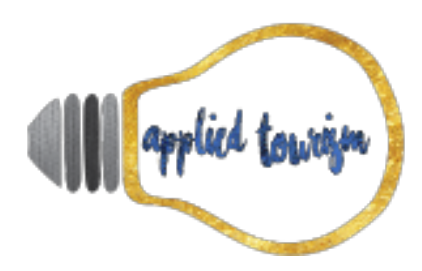

Volume 3, número 1, 2018, p. 127-146

\section{REFERÊNCIAS}

Brasil. (2000). Lei n. ${ }^{\circ}$ 9.985, de 18 de julho de 2000. Institui o Sistema Nacional de Unidades de Conservação da Natureza e dá outras providências. Diário Oficial da União do Brasil. Brasília, DF.

Gerhardt, C.; Robles, R. A.; Rodrigues, C. G. O.; Santos, A. J. B.; Vale, do T. F.; Moreira, J. C. (2015). O ciclo de palestras ambientais do Projeto Tamar de Fernando de Noronha-PE e a percepção dos visitantes. In: Encontro De Pesquisa De Fernando De Noronha, São Pedro E São Paulo EAtol Das Coras, 1., 2015, Fernando de Noronha, Anais eletrônicos... Fernando de Noronha: ICMBio, p.196-200.

Icmbio. Unidades de Conservação - Marinho. Disponível em: <http://www.icmbio.gov.br>. Acesso em: 07 de abr. 2017.

Icmbio. Plano de manejo: APA Fernando de Noronha - Rocas - São Pedro e São Paulo. Disponível em: < http://www.icmbio.gov.br > . Acesso em: 09 de abr. 2005.

Marshall, O.; Jenkins, D.; Cleary, D. (2009). The Rough Guide to Brazil. Penguin, London.

Moreira, J. C. et al. (2015). Os Benefícios de um Geopark e a proposta de um Geopark em Fernando de Noronha. In: Encontro De Pesquisa De Fernando De Noronha, São Pedro E São Paulo E Atol Das Rocas, 1., 2015, Fernando de Noronha, Anais eletrônicos... Fernando de Noronha: ICMBio, p. 191-195.

Moreira, J.C; Robles, R.A; Belini, C. (2009). As Palestras como Meio Interpretativo: Estudo de Caso com Palestrantes em Fernando de Noronha (PE). Revista Brasileira de Ecoturismo. São Paulo, v.2, n.4, p. 322.

Parque Nacional Marinho Fernando De Noronha. Informações Parque Nacional Marinho Fernando de Noronha. Disponível em: < http://www.parnanoronha.com.br> . Acesso em: 12 de abr. 2017.

Pessoa, G. T. (2014). Fernando de Noronha: uma ilha-presídio nos trópicos (1833-1894). Rio de Janeiro: Arquivo Nacional, p. 54.

Projeto Tamar. Bases de pesquisa. Disponível em: < http://www.tamar.org.br>. Acesso em: 13 de abr. 2017.

Ramos, L. Fernando de Noronha bate recorde de visitação em 2016. PANROTAS, São Paulo, jan. 2017 Disponível em: < http://www.panrotas.com.br> Acesso em: 07 de abr. 2017.

Unesco. Islas atlánticas brasileñas: Reservas de Fernando de Noronha y Atolón de las Rocas. Disponível em: < http://portal.unesco.org > . Acesso em: 11 de abr. 2017.

WwF. Unidades de Conservação: O que é uma unidade de conservação?. Disponível em: $<$ http://www.wwf.org.br> . Acesso em: 07 de abr. 2017. 